\title{
Empirical Study of Citizen Happiness Based on Individual Characteristics and Life Indexes
}

\author{
Sun Yujin ${ }^{1, *}$ and Chen Kang $^{2}$ \\ ${ }^{1}$ School of Engineering Management, Suzhou University, Suzhou 234000, P.R. China; ${ }^{2}$ Department of Ideological and \\ Political Theory Teaching, Suzhou University, Suzhou 234000, P.R. China
}

\begin{abstract}
: validation research is carried out in this paper to find out whether happiness of citizens with different individual characteristics and life indexes is different, and what factors exert an influence on happiness. 271 urban residents were taken as the survey respondents, and stratified sampling was employed in this research to compare and analyze happiness of citizens with different individual characteristics and life indexes. Pearson's Correlation Coefficient was used to determine the relationship among the three, and a standardized regression equation was established to construct the model influence for citizen happiness. The research findings illustrate that the relationship of family and marriage, income, generations and living environment can predict the happiness level of citizens, and that economic factor is still crucial to prefecture-level cities in the middle. Recommendations are countermeasures are presented as per the findings.
\end{abstract}

Keywords: Empirical analysis, happiness, individual characteristics, living index.

\section{INTRODUCTION}

The Chinese dream is to achieve national prosperity, national revitalization and people's happiness. The dream carries the beliefs and ideals of the people, and shows their eager anticipation of a stable job, satisfactory income, comfortable living conditions, reliable social security and beautiful living environment, access to better education, and a high level of medical and health services. Therefore, one of the basic connotations of the Chinese dream is to let everyone live a more prosperous and dignified life and realize free and overall development. Under the declaration and guidance of the Chinese dream, the Chinese government has accelerated the pace of urbanization and improved the urbanization quality. Premier Li Keqiang has pointed out that the core of urbanization is the "urbanization of people", and the purpose of urbanization is to make people better off and to let people feel happy.

Research into the happiness of urban residents meets the needs of the times and reflects the social mainstream public opinions. Studies on happiness have been the hotspots and focuses that attract academic attention. There is now a large amount of domestic and international research literature on happiness.

Foreign scholars mainly set from the following aspects. Easterlin explored the relationship between happiness and income, and presented the famous Easterlin paradox [1]. Diener analyzed the external and internal factors affecting happiness [2]. Senik et al. explored the impact of income on happiness. Ravallion and Lokshin studied the impact of unemployment on personal well-being; Wolfers studied the influence of inflation on life satisfaction [3]. Kotakorpi and Laamanen investigated the interaction between the Finnish government spending and happiness of residents from the viewpoint of government spending. From the angle of the environment, Welsch explored the relationship between environmental pollution and happiness. In addition, some scholars made investigation of the relationship between urbanization and happiness. Further, Gerdtham and Johannesson found by conducting studies that urban residents in Sweden had exhibited higher levels of happiness than those living in large cities [4]. On the contrary, by analyzing China's survey data, Knight and Gunatilaka reported lower levels of happiness in urban residents than in rural residents [5].

Domestic studies on happiness are mainly deployed around the following aspects. Research is conducted from the philosophical point of view, such as Yu Xiaoquan's exploration of the philosophical significance of the Marxist Concept of Happiness [6], and also from the psychological point of view, such as discussions of the psychology of happiness by Zheng Xue et al. [7]. Some research is set forth from the economic perspective, like Chen Huixiong's investigation into the relationship between economic and social development and national happiness [8]. There are studies from the perspective of the current status of resident happiness, such as Fang Gang's study of the differences in happiness between urban and rural residents [9]. Further, factors that affecting happiness of residents are talked about. For example, Xing Zhanjun studied the happiness indexes of residents from six capital cities as well as exploring the factors that affecting happiness of residents [10]. A number of scholars make research from the viewpoint of happiness measurement, and compile a happiness index system, including the "Subjective Well-Being Scale for Chinese Urban Residents" by Xing Zhanjun [11], the "Comprehensive Happiness Questionnaire" compiled by Miao Yuanjiang that 
explores the well-being and happiness index [12]. Furthermore, some research makes interpretation from a sociological point of view, and sociological research mainly studies the quality of life and life satisfaction degree, like Zhou Changcheng's exploration of subjective quality of life and the indicators [13]. There are also some studies from other angles. For instance, Ning Xueping studied China's housing consumption credit and happiness index of residents [14]; Sun Sanbai conducted a study of happiness of urban migrants from the perspectives of migratory behavior and household register [15]; Meng Xiangfei studied happiness of residents from the perspective of social cohesion, holding that social cohesion and happiness of residents were significantly correlated [16]; uniquely, Zhang Chuwen and $\mathrm{Xu}$ Yanhui measured the happiness index of elderly people in rural areas in Hunan Province [17]. The government is also concerned about happiness research, and plenty of cities have carried out investigations into the happiness of residents. As can be seen from the above examples, previous studies mostly focused on the demographic variables, the economic variables and psychological variables, and discussed the research objects as a single individual or in a closed space. However, they have all ignored that the individuals are living in the society and growing in the socialization process. Inevitably, they cannot be studied without the real daily life, so the daily life factors will inevitably have an impact on happiness. Nevertheless, there were relatively few previous studies that investigated the impacts of individual characteristics and daily life indicators on happiness. In this case, this study attempts to combine individual factors and daily life indicators with the purpose of investigating their effects on happiness. Additionally, the following five hypotheses have been put forward.

Hypothesis 1: There are significant gender differences in the level of happiness

Hypothesis 2: There are significant differences in the level of happiness between residents with different educational degree

Hypothesis 3: There are significant differences in happiness level between residents of different marital status;

Hypothesis 4: There are significant age differences in the level of happiness

Hypothesis 5: People's daily life index has a significant impact on happiness.

In this study, as a typical central prefecture-level city, SZ City in Anhui Province is taken as an example, as it is an epitome for many cities in China. The findings may provide policy support to the construction of central prefecture-level cities and provide decision references for improving the happiness of residents.

\section{RESEARCH METHODS}

\subsection{Research Objects}

A survey was conducted amount SZ city residents who were taken as the research samples. Stratified sampling method was employed, and 5 streets were extracted from SZ City, with 60 residents randomly selected from each street for the survey. A total of 300 questionnaires were returned, including 271 valid questionnaires, with the effective rate of $90.3 \%$. In terms of gender, there were 146 male residents and 125 female residents. As for age, 72 people aged below 35 years old, 181 people aged between 35-60 years old, and 181 people aged above 60 years old. In regard to education degree, 4 people were illiterate; 25 people graduated from elementary schools; 87 people graduated from junior schools and 103 from technical secondary schools or high schools; 52 people held a bachelor's degree or above. With reference to marital status, 20 people were married; 241 people were married; 4 people were widowed; 4 people divorced and 2 people were of other status.

\subsection{Research Tools}

This study used the self-made questionnaire "Urban Citizens' Subjective Quality of Life". The entire questionnaire was composed of a total of six subscales, which are happiness, neighborhood relationship, family and marriage relationships, income, leisure lifestyle content and living environment. Likert Scale Scoring was applied in the entire questionnaire, and the overall a coefficient of the questionnaire was 0.827 , showing good content validity and construct validity.

\subsection{Research Methods}

The collective surveying approach was employed in the investigation. After encoding the survey data collected into the computer, the SPSS16.0 software was used for data processing and analysis, and a model for factors that influencing happiness level of residents was constructed based on the results of multiple regression analysis. First, as per the realistic theory, the hypothesis model (see Fig. 1) was built as follows.

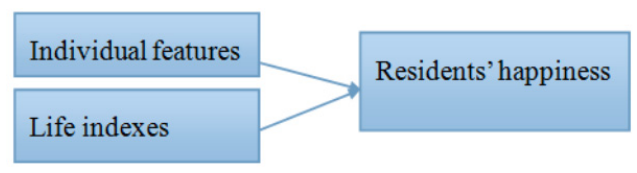

Fig. (1). Hypothesis model.

\section{RESULT ANALYSIS}

\subsection{Comparative Analysis of Happiness of Residents with Different Individual Characteristics and Life In- dexes}

A variation analysis was carried out, with the independent variables including gender, age, education level, family algebra and affordability of housing price, views on family relations, evaluation of marriage, family economic level, views on economic conditions improvement, income satisfaction, security and environmental pollution, and the dependent variable of happiness level. The results are shown in Figs. (2 and 3).

According to Fig. (2), the happiness level of residents distributed in the $\mathrm{W}$ shape in terms of age; people aged below 30 years old and above 60 years old had the highest level of happiness, followed by 40-50 years old, and people aged between 30-40 years and 50-60 years old exhibited the lowest level of happiness. On the educational level, the happiness of residents gradually improved with the education level, also presenting a gradually increasing trend. 


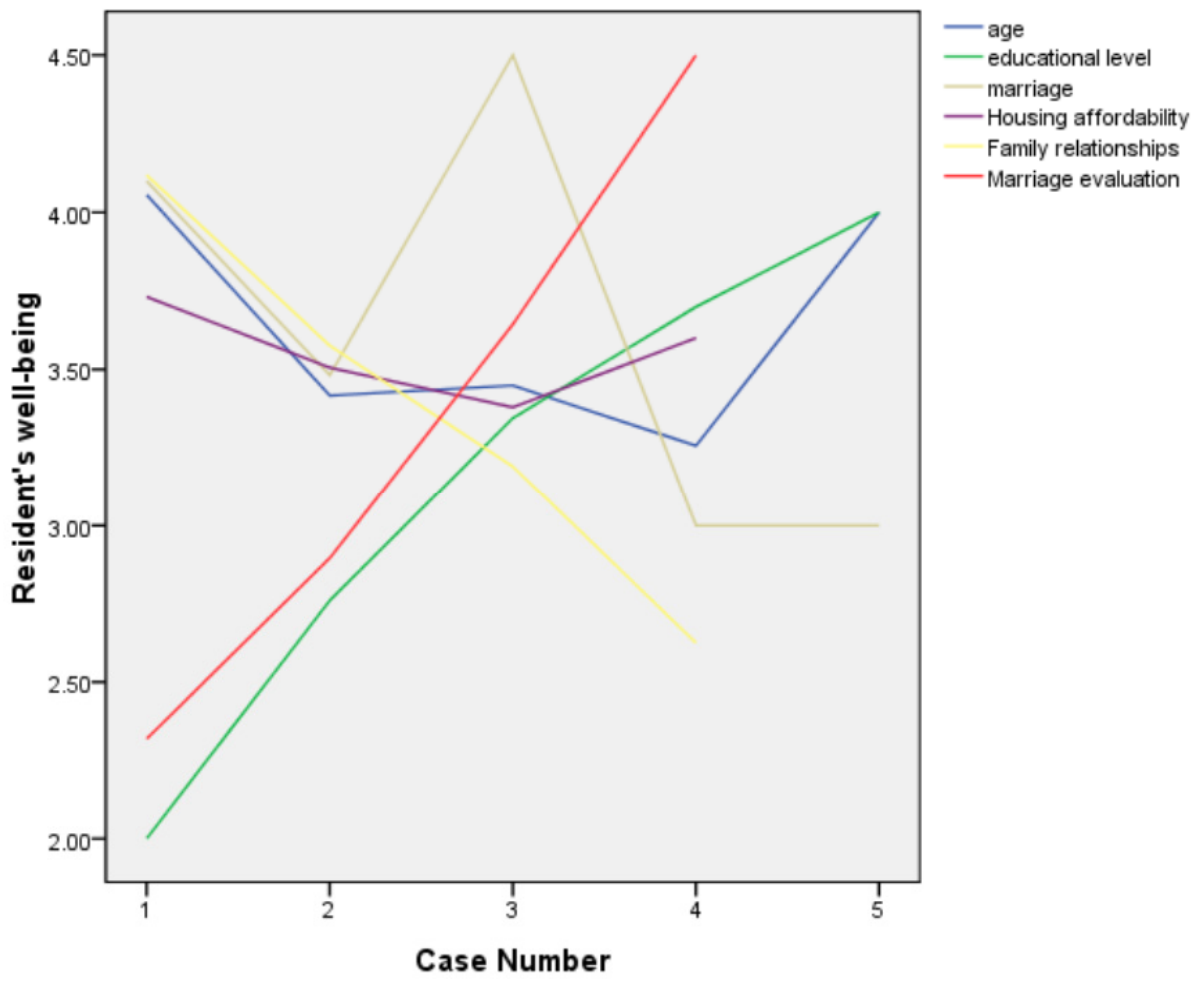

Fig. (2). Line chart of happiness of residents with different individual characteristics and life indexes.

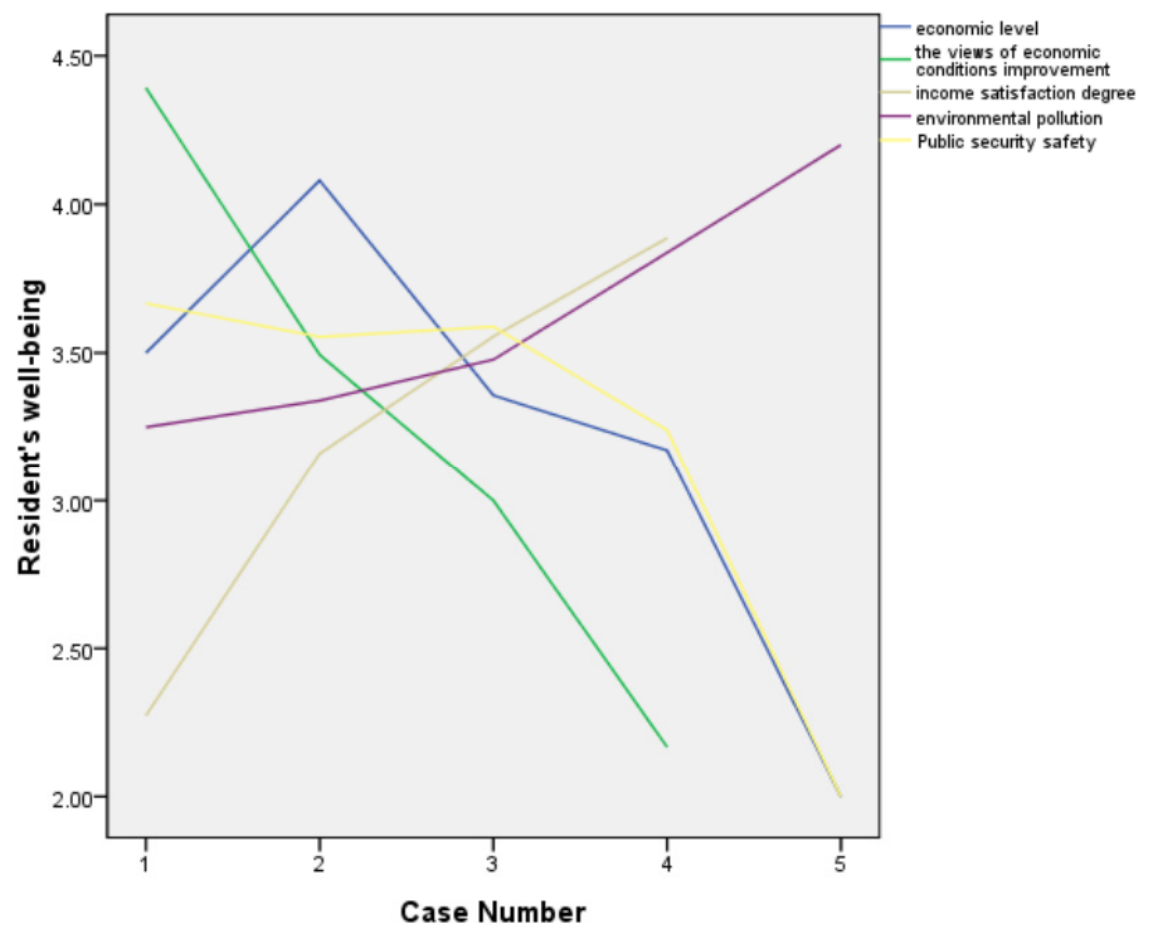

Fig. (3). Line chart of happiness of residents with different life indexes.

As for satisfaction with the income, happiness of residents gradual increased with increasing satisfaction with the income, also showing a gradually increasing trend. On marriage, happiness level of unmarried residents ranked the highest, and that of married people ranked the lowest. In terms of evaluation of marriage, as the residents became more satisfied with the evaluation of marriage, their happiness level became higher.
In regard to family relationships, the more harmonious the family relations, the higher the level of happiness.

As per Fig. 3, with regards to affordability of housing prices, residents who claimed to be quite affordable had the highest level of happiness, followed by residents who found it extremely difficult to bear, followed by residents who 
could just afford them, and lastly residents who found it a little difficult to bear. As for residents' self real economic level, the happiness of residents exhibited an increasing trend with better economic level of families. With reference to the opinions on the whole socio-economic conditions, residents who were more pessimistic about the socioeconomic development presented lower levels of happiness, while those that were more optimistic about the socioeconomic development exhibited higher levels of happiness. On the issue of the social environment, residents who considered the current social environment pollution to be more severe presented higher levels of happiness, while those that cared little about the social environmental pollution problems had lower levels of happiness. As for the category of social security; residents who considered the current social security to be poorer presented lower levels of happiness; on the contrary, residents gained higher levels of happiness.

Data analysis results show that there were no significant differences in happiness level of residents in the categories of gender, affordability of housing prices, family relationships and social order and security, which disproved Hypothesis 1 . On the other hand, there were significant differences in age, education level, family algebra, marital status, marital evaluation, family economic level, opinions on improvement of the economic conditions, income satisfaction, environmental pollution, among many others, which proved Hypotheses 2, 3, and 4.

\subsection{Correlation Analysis Between Residents' Individual Characteristics, Life Index and Happiness}

In this study, the Pearson's correlation analysis was made to find out the correlation between the happiness level and the individual characteristics and life indexes of residents, in order to determine the relationship between the three factors. The results are displayed in Table 1. Correlation analysis findings show that the happiness level reached very significant association level with residents' living environment, neighborhood, family and marriage relationships, leisure lifestyle content, and income, while association with other factors has also reached significant levels.

\subsection{Regression Analysis of Residents' Individual Characteristics, Life Indexes and Happiness and Model Building}

To further explore the influential power of residents' individual characteristics, life indexes and happiness, a multivariate regression analysis was made by using the Stepwise method, with independent variables of residents' individual characteristics and life indexes, and the dependent variable of residents' happiness, as shown in Table 2 . The multiple regression analysis shows that residents' individual characteristics and life indexes had a higher predictive effect on happiness, with the predictive value of up to $49.5 \%$.

As can be seen from Table $\mathbf{2}$, the relationship of family and marriage, income, generations and living environment can predict the happiness level of residents; their combined explanatory variable is 0.495 , which means that these indicators can be combined to predict $49.5 \%$ of the happiness level of residents. In accordance with the regression model, the relationship of family and marriage first entered the regression equation, which could explain $31.6 \%$ of the variance in happiness of residents. The next to enter the regression equation was income, which could explain $11.2 \%$ of the variance in happiness of residents. Afterwards it was generations, which could explain 5\% of the variance in happiness of residents. And finally it came to the living environment, which could explain $1.7 \%$ of the variance in happiness of residents. Therefore, the standardized regression equation was established: Residents' happiness $=$ family and marriage relationships $\times 0.515+$ income $\times 0.356+$ generations $\times(-0.203)+$ living environment $\times 0.138$.

A multiple regression analysis was made based on the above results, and the modeling diagram can be constructed between residents' happiness, individual characteristics, and living index coefficient, as shown in Fig. (4).

\subsection{Conclusion}

\subsubsection{Economic Factor is the Key to Affecting Happiness}

Figs. (2 and 3) demonstrate that with higher the income and economic level, people feel happier. In the standardized regression equation constructed in this study, income can explain $31.6 \%$ of the variance in happiness of residents, signifying that on the basis of a stable and harmonious family, the most important factor affecting people's happiness is still economic factor. Only after the economic income reaches a certain level will people take into account other factors that affect happiness. To this end, raising the economic income levels is still indispensable to the construction of central prefecture-level cities.

\subsubsection{SZ City is Focused on Tradition}

As can be seen from Fig. (2), there is a positive relationship among family relationship, marriage and happiness.

Table 1. Correlation analysis between residents' individual characteristics, life index and happiness.

\begin{tabular}{|c|c|c|c|c|c|}
\hline & Happiness & $\begin{array}{c}\text { Living } \\
\text { Environment }\end{array}$ & Neighborhood & $\begin{array}{c}\text { Family \& } \\
\text { Marriage Relation }\end{array}$ & $\begin{array}{c}\text { Leisure Life } \\
\text { Content }\end{array}$ \\
\hline Living environment Neighborhood & $.027 * *$ & 1 & & & \\
\hline Family \& marriage relation & $.305 * *$ & $.415^{* *}$ & 1 & & \\
\hline Leisure life content & $.641 * *$ & .035 & $.153^{*}$ & 1 & \\
\hline Income & $-.477 * *$ & $-.150 * *$ & $-.133 *$ & $-.317 * *$ & 1 \\
\hline
\end{tabular}


Table 2. A multivariate regression analysis of residents' individual characteristics, life indexes and happiness.

\begin{tabular}{|c|c|c|c|c|c|c|c|}
\hline Model & R & R Square & $\begin{array}{c}\text { Adjusted R } \\
\text { Square }\end{array}$ & $\begin{array}{c}\text { Std. Error of } \\
\text { the Estimate }\end{array}$ & $\begin{array}{c}\text { R Square } \\
\text { Change }\end{array}$ & F Change & Sig. F Change \\
\hline \hline 1 & $.562^{\mathrm{a}}$ & .316 & .311 & .74563 & .316 & 54.613 & .000 \\
2 & $.654^{\mathrm{b}}$ & .428 & .419 & .68477 & .112 & 22.906 & .000 \\
3 & $.691^{\mathrm{c}}$ & .478 & .464 & .65716 & .050 & 11.041 & .001 \\
4 & $.704^{\mathrm{d}}$ & .495 & .478 & .64902 & .017 & 3.925 & .050 \\
\hline
\end{tabular}

a. Predictors: (Constant), relation of family and marriage

b. Predictors: (Constant), relation of family and marriage, income status

c. Predictors: (Constant), relation of family and marriage, income status, generations

d. Predictors: (Constant), relation of family and marriage, income status, generations, living environment

\begin{tabular}{|c|c|c|c|c|c|}
\hline \multicolumn{9}{|c|}{ ANOVA $^{\mathrm{e}}$} \\
\hline \hline Model & Sum of Squares & df & Mean Square & F & Sig. \\
\hline Regression & 47.525 & 4 & 11.881 & 28.206 & $.000^{\mathrm{d}}$ \\
Residual & 48.442 & 115 & .421 & & \\
Total & 95.967 & 119 & & \\
\hline
\end{tabular}

d. Predictors: (Constant), relation of family and marriage, income status, generations, living environment e. Dependent Variable: positive happiness

\begin{tabular}{|c|c|c|c|c|c|c|}
\hline \multicolumn{7}{|c|}{ Coefficients $^{\mathrm{a}}$} \\
\hline \multirow[t]{2}{*}{ Model } & \multicolumn{3}{|c|}{ Unstandardized Coefficients } & \multirow{2}{*}{$\begin{array}{c}\begin{array}{c}\text { Standardized } \\
\text { Coefficients }\end{array} \\
\text { Beta }\end{array}$} & \multirow[b]{2}{*}{$\mathbf{t}$} & \multirow[b]{2}{*}{ Sig. } \\
\hline & & B & Std. Error & & & \\
\hline \multirow{4}{*}{4} & (Constant) & 1.971 & .485 & & 4.067 & .000 \\
\hline & Income & .489 & .094 & .356 & 5.198 & .000 \\
\hline & For generations & -.265 & .088 & -.203 & -3.013 & .003 \\
\hline & $\begin{array}{l}\text { Living environ- } \\
\text { ment }\end{array}$ & .138 & .069 & .138 & 1.981 & .050 \\
\hline
\end{tabular}

a. Dependent Variable: positive happiness

Table 1 exhibits a significant correlation between neighborhood, family and marriage relationships and happiness. According to residents' happiness influence model in Fig. (4), it is obvious that family and marriage relationship and generations have an impact on residents' happiness. As a result, SZ City is focused on tradition and profoundly imbued with traditional culture. It especially values family relationships, which is in good agreement with Fan Xinghong's findings [18]. This shows that a city's cultural heritage and tradition will exert profound impacts on people's lives. This factor should be taken into account in livelihood, and considerable attention should be paid to the guiding and identity role of communities in a city.

\subsubsection{Urban Construction Work Needed to be Strength- ened}

From Table 1, a correlation analysis of residents' individual characteristics, life indicators and happiness shows that the living environment, leisure lifestyle content and happiness are correlated. The living environment enters into the regression equation, indicating that residents have begun

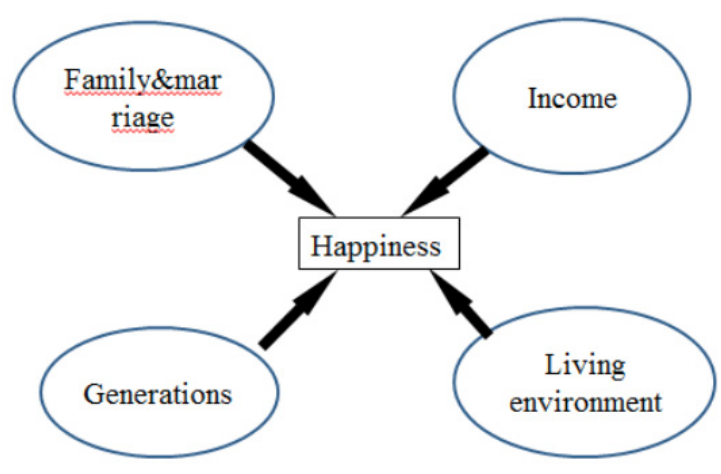

Fig. (4). Influence model for residents' happiness. 
to focus on the living environment and leisure life and begun to focus on the quality of life in cities, thus putting forward higher requirements about urban construction and urban management.

\section{COUNTERMEASURES AND SUGGESTIONS}

\subsection{Vigorously Develop the Economy, Provide and Cre- ate More Jobs, Improve Residents' Income}

When considering the economic and social development, the promotion of employment should be given priority to. In addition, continue to accelerate the transformation of economic development pattern, make innovation of the development model and improve the quality of development. Urban economic circle development should highlight the development features, strengthen industrial integration, strengthen the division of labor, promote the sharing of resources, provide more employment opportunities, and perfect all systems to protect people's livelihood.

Implement a proactive employment policy; promote high-quality employment; strengthen human resources market construction; implement the talent sharing mechanism in the urban economic circle; gradually form a talent development mechanism integrating policy coordination, service penetration, and resource sharing. Through the economic development, create jobs; raise incomes of residents in many ways; promote synchronous income growth and economic development, and make lives of residents better off so as to enhance happiness and further improve happiness index of residents.

\subsection{Increase the Livelihood Efforts, Keep Innovating Service Platform, and Optimize Urban Community Building}

Begin work with improving people's livelihood. Give full play to the active role of communities, let residents share the fruits of development; build activity platforms in communities; enhance residents' happiness index. Encourage residents to participate in community building and care about community development to improve their enthusiasm and inspire their sense of belonging, identity and satisfaction in the community.

At the same time, actively innovate information platform and smoothen residents' appeal channels. Residents can express their appeals and discontent and propose comments and suggestions, such as building a service platform to facilitate their life and work. Give full place to social workers; establish volunteer studio; strengthen interactive communications with residents. Also, make use of the websites, microblogging, WeChat, QQ and other new media ways to collect all kinds of advice and service needs to improve community services and management.

4.3. Strengthen Urban Construction, Constantly Improve the Urban Public Service System, Improve the City Service Level

Establish a new city concept; give full play to urban planning functions; build a civilized, comfortable and livable city; beautify the urban environment; and improve urban services. In urban planning, expand space from industrial development, infrastructure, public services, supporting functions and ecological civilization construction; keep improving the urban functional quality; strengthen peopleoriented management in particular; let every resident in the city feel happy with a good city image, perfect facilities and human services.

At the same time, continue to improve urban public service system; provide residents with high-quality, all-round services; strengthen urban planning, plant more large-scale city greenbelts, improve urban quality. Continue to improve the city's carrying capacity; create the cultural taste and ecological image of the city; protect traditional culture and improve the environment's bearing capacity, build a livable city. Enhance environmental protection awareness; start from improving air quality, so as to create a comfortable and healthy living space for residents. Accelerate the pace of constructing a smart city; let science and technology better serve the city. These are important factors not only reflecting the external image of the city as a whole, but also improving happiness of residents.

\subsection{Focus on the Protection of Traditional Culture, Ex- tend and Create Based on Inheritance}

In the process of urbanization, special attention should be paid to protecting traditional culture. Every city has a rich cultural spirit and contains abundant historical and cultural values. Protect the traditional heritage and promote traditional culture while developing economy. Image of urban culture is the extension and internal manifestation of urban economy and social system culture. Therefore, retain our excellent traditional culture in the urbanization process; actively integrate into the nurturing and practice of socialist core values; carry forward, update and create cultures by combining with the reality; give more positive energy.

President Xi Jinping said, "people's aspirations for a better life is our objective of the struggle." Hence, how to include residents' happiness into the Chinese dream, and how to change happiness into warm feelings in the urbanization course, thus opening up a journey of happiness is the direction and motivation for the studies regarding happiness.

\section{CONFLICT OF INTEREST}

The authors confirm that this article content has no conflict of interest.

\section{ACKNOWLEDGEMENTS}

This work is supported by the Key Project of The young talents Fund Project of Anhui Province: The study on the construction of the public service system of Local university campus, authority No.:2013SQRW077ZD, 2014.01 2015.12, The open issue on the center of the university culture research of the key research base of humanities social sciences Anhui province: The study on the strategy of Suzhou city social economic and cultural development, authority No.:2011YKF25, 2011.01 2014.12., and The project on the promotion ability of Suzhou University to serve the local economic and social development:The study of constructing Suzhou city public service system,authority No.:szxyfwdf2013010, 2014.01 2019.12. 


\section{REFERENCES}

[1] H. Ren, Happiness research from economic perspective in China-with reference to happiness economics development of foreign countries, East China Normal University, pp. 8-22, 2012.

[2] E. Diener, "Subjective well-being," Psychology Bulletin, no. 03, pp. 542-575, 1984.

[3] Wolfers, "Is business cycle volatility costly Evidence from surveys of subjective well-being," International Finance, vol. 6, no. 01, pp. 1-26, 2003.

[4] Y. Lu, and T. Wang, "The view of study for the effect factors or subjective well-being," Economic Perspectives, vol. 05, pp. 125130,2010

[5] W. Li, The study of well-being of land-lost farmers--based on the perspective of human ecology, ZheJiang University, pp. 12-35, 2009.

[6] X. Yu, The Philosophic Implication of Marx Well-Being, Jilin University Press, 2008.

[7] X. Zheng, B. Yan, L. Qiu, and X. Zhang, The Psychology of Happiness, Jinan University Press, 2004.

[8] H. Chen, The Economic and Social Development and National Happiness, Zhejiang University Press, 2008.

[9] G. Fang, and X. Feng, "Research on subjective well-being differences between urban and rural residents and their influence factors- -take Chengdu city as a case," Population and Development, no. 06, pp. 74-81, 2009.

[10] Z. Xing, and X. Liu, The Report of Happiness Index for the Urban Well-Being from Six Provincial Capital--Chengdu City as an Example, Social Sciences Academic Press, 2008.

[11] Z. Xing, and Y. Zhang, "Study of the relationship of Social Support and Subjective Well-being," Social Science Research, no. 06, pp. 9-14, 2007.

[12] Y. Miao, Happiness of Psychologic Vision: The Study of Happiness Theory and Assessment," Tianjin Peoples publishing House, 2009.

[13] C. Zhou, "The subjective living quality: construction and assessment of index," Social Sciences Academic Press, 2008.

[14] X. Ning, The China Housing Consumption Credit and the Index of Resident's Well-Being, Social Sciences Academic Press, 2011.

[15] S. Sun, and J. Bai, "Migration hukou identity and happiness of urban migrants," Economic Review, no. 6, pp. 101-112, 2014

[16] X. Meng, "Study of social cohesion and residents' well-beingbased on datas of shenzhen and xiamen," Tianfu New Idea, no. 01, pp. 122-130, 2014

[17] C. Zhang, and Y. Xu, "The assessment of countryside olders wellbeing's index," Statistics \& Decision, no. 24, pp. 64-67, 2011.

[18] X. Fan, and J. Tang, "The path analysis of Anhui transtion and residents' well-being," Jiang-huai Tribune, no. 06, pp. 132-136, 2012.

Received: June 10, 2015

Revised: July 29, 2015

Accepted: August 15, 2015

(C) Yujin and Kang; Licensee Bentham Open.

This is an open access article licensed under the terms of the (https://creativecommons.org/licenses/by/4.0/legalcode), which permits unrestricted, noncommercial use, distribution and reproduction in any medium, provided the work is properly cited. 